\title{
DOS LIBROS Y UN DESTINO
}

\author{
Jordi Crespo Saumell \\ Universitat Pompeu Fabra \\ cresaumell@gmail.com
}

Recibido: 15 de marzo 2021. Aceptado 5 de abril de 2021.

Cómo citar este artículo/Citation: Crespo Saumell, Jordi (2021) "Dos libros y un destino", Asclepio, 73(1): p352. https://doi. org/10.3989/asclepio.2021.18

Copyright: @ 2021 CSIC. Este es un artículo de acceso abierto distribuido bajo los términos de la licencia de uso y distribución Creative Commons Reconocimiento 4.0 Internacional (CC BY 4.0)

Moller, Violet. The Map of Knowledge. How Classical Ideas Were Lost and Found: A History in Seven Cities. Londres, Picador, 2019, VIII + 331 páginas [ISBN: 13: 978-1509829620 (tapa blanda)].

Greenblatt, Stephen. The Swerve. How the World Became Modern. Nueva York / Londres, W. W. Norton \& Company, 2011, XIII + 263 páginas [ISBN: 978-0-393-34340-3 (tapa blanda)]

Habent sua fata libelli... tal es, sin duda, el marco general que propicia el argumento de los dos libros de esta reseña. Ambos empiezan, también, con una alusión pictórica: a la Escuela de Atenas de Rafael el de Moller. The Map of Knowledge. How Classical Ideas Were Lost and Found: A History in Seven Cities; y al Nacimiento de Venus de Botticelli el de Greenblatt The Swerve. How the World Became Modern. Dos libros pergeñados en el ámbito anglosajón que, inspirándose en una pintura, tienen por objeto común contar el azaroso periplo de distintos textos científicos / filosóficos desde la Antigüedad hasta nuestros días. Estas coincidencias albergan, sin embargo, notables diferencias.

Existen una serie de factores que determinarán lo que el lector va a encontrar en el libro de V. Moller. Tal y como adelanta en el prefacio (Moller, 2019, p. 10), el marco teórico del que parte la autora es el de la historia intelectual. Esto implica que parte importante de la atención del libro se centre en aquellos aspectos contextuales (sociales, históricos, económicos, técnicos, etc.) que propiciaron la producción, transmisión y traducción del saber contenido en los tratados de Euclides $^{1}$, Ptolomeo y Galeno. Esta perspectiva amplia favorece el carácter exotérico del libro, pero puede hacer que el lector especializado, que busque profundizar en el tema, pueda sentir que algunos pasajes o incluso el tono general del libro carezcan del rigor y de la exactitud a los que pueda estar avezado.

En segundo lugar, la dificultad de abordar un tema harto complejo como el de la transmisión textual se ve sin duda acrecentada por las cuestiones inherentes a la transmisión de las tres disciplinas - matemáticas, astronomía y medicina - de las que el libro intenta dar cuenta, disciplinas cuyas tradiciones, incluso por separado, son ya de por sí intrincadas. Por otro lado, esta dificultad se ve todavía incrementada por el hecho de querer trazar los avatares de dichos contenidos a lo largo y ancho de un arco espacio temporal que abarca siete enclaves geográficos durante prácticamente diez siglos. Por estas razones, el lector con conocimientos filológicos, que esté acostumbrado a manejarse entre stemmata codicum y los entresijos propios de la ecdótica encontrará en el libro de Moller un divertimento que, casi seguro, no azuzará su interés por falta de información, o lo que es peor en algunos casos, por falta de precisión. En efecto, el carácter divulgativo de un 
libro no debería ir reñido con el rigor pero esto es algo que encontramos en algunos pasajes del libro:

« No era tarea fácil (i.e. la traducción de textos árabes al latín). El árabe es una lengua extremamente compleja en el que el alfabeto y el sentido de la escritura son diferentes, y con un intrincado sistema de diacríticos, pero estaba repleto de mozárabes en las inmediaciones dispuestos a ayudar » (Moller, 2019, p. 147).

Cualquier persona medianamente acostumbrada a traducir entre lenguas que pertenezcan a distintas familias lingüísticas sabe que, salvo en los primeros intersticios, el mayor problema que supone esta tarea no es tanto el de la descodificación de un alfabeto (o sistema de escritura diferente al latino) como el de la dificultad para encontrar correspondientes homeomórficos para conceptos de la lengua 1 en la lengua 2 , especialmente, cuando la lengua de origen y la lengua objeto pertenecen a ambientes culturales muy dispares, muy alejados en el espacio y en el tiempo, o cuando el contenido del texto a traducir contiene gran cantidad de tecnicismos o de realidades abstractas ajenas a la lengua de destino. Así, aunque se partiera de un alfabeto distinto y no estuviera exenta de dificultades, la traducción de textos griegos al latín fue empresa habitual del s. I a.C. en adelante; pero cuando el misionero jesuita Mateo Ricci (s. XVI) emprendió - al lado del matemático Xu Guangxi - la primera traducción al chino del libro de los Elementos de Euclides (en 13 volúmenes) ${ }^{2}$ los dilemas que se le presentaron y a los que tuvo que hacer frente debieron ser de una índole muy distinta a la problemática a la que apunta Moller. En esta misma linea, al final del libro (Moller, 2019, p. 280) la autora británica afirma que una de las razones del declive de la cultura árabe y del auge de la cultura cristiana/europea a finales de la Edad Media consistió en el hecho de que la escritura árabe, por sus características, no se adaptó a las exigencias de la imprenta de tipos móviles de J. Gutenberg; pero, ¿acaso el chino, una escritura "mucho más compleja" que el árabe, no fue llevado a la imprenta siglos antes de la aparición del invento de Gutenberg salvaguardando con ello buena parte del acervo cultural de una de las mayores naciones del mundo?

The Map of Knowledge ofrece como mínimo otro ejemplo de la dificultad que supone conciliar el carácter divulgativo con el rigor. En esta ocasión el yerro llega de la mano de la medicina, en concreto, del descubrimiento de un tratado de Galeno en 2005:

" In the course of their searches for manuscripts, humanist scholars had inevitably discovered previously unknown works by Galen (there is an apparently almost inexhaustible supply - new ones are occasionally unearthed even today, almost 2,000 years after they were written). Examining these new treatises made scholars aware of aspects of Galenic medicine not present in the Arabic and medieval traditions [...] " (Moller, 2019, p. 272)

Si, por un lado, Moller está al tanto del hallazgo y lo considera suficientemente relevante como para incluirlo en su libro; por otro lado, la presentación de la autora puede llevar al lector a hacerse una idea equivocada del asunto. Primeramente, Moller omite datos importantes acerca del texto descubierto: el título del tratado galénico ha sido harto discutido, y puede traducirse de distintas maneras (también en inglés); además, se trata de una carta, de una misiva que Galeno escribe a un amigo que le pide que le cuente qué tipo de "disciplina" sigue para haber podido continuar con sus asuntos sin afligirse a pesar de haberlo perdido todo en el gran fuego que arrasó Roma en el 192 d.C. En consecuencia, la parca información que proporciona el libro de Moller hará que el lector no llegue a advertir que el hallazgo en cuestión no es un texto médico sino un relato autobiográfico de contenido moral/filosófico.

En segundo lugar, no es verdad que se trate de un texto desconocido. Se sabía que Galeno lo había compuesto pero se daba por perdido - como sucede con un alto porcentaje de la producción literaria de la Antigüedad que no ha llegado hasta nosotros; por ende, no es un descubrimiento absolutamente de novo. En el capítulo XII de su libro De libris propiis, Galeno da un listado de 23 tratados de temática ética entre los que se encuentra uno que lleva el mismo título 4 que el de la misiva que en el 2005 encontrara A. Pietrobelli en el manuscrito Vlatadon 14 en el homónimo monasterio de Tesalónica. Una cosa es que en esta misma obra Galeno nos cuente que en la biblioteca Palatina de Roma había encontrado libros que no se conocían o que no estaban registrados en los catálogos (Boudon - Millot, Jouanna, Pietrobelli, 2010, p. 7; Rashed, 2011, p. 61) y $^{5}$ otra cosa, bien distinta, es lo que Moller da a entender en el fragmento acerca del descubrimiento de nuevos tratados de Galeno desde el Renacimiento hasta hoy.

En tercer lugar, tampoco es cierto - como parece desprenderse del fragmento del libro de Moller - que no se conservara nada en árabe de dicho tratado. En lo concerniente a este hallazgo, la primera mención al texto se remonta a un compendio del s. IX titulado Risala de Hunain ibn Ishaq. I. Garofalo, editor y cotraductor del opúsculo de Galeno al italiano, informa que el título ya se conocía antes del descubrimiento del De indolentia en el 2005, y que algunos extractos de di- 
cha obra se conservaban precisamente en hebreo y en árabe (Garofalo, 2013, pp. $441-442)^{6}$. El manuscrito Vlatadon 14 da testimonio de textos conocidos pero que o bien no se conservaban, o bien se conservaban fragmentariamente, o bien no se conservaban en griego: el de De indolentia correspondería a la tercera de estas posibilidades.

Las razones hasta aquí esgrimidas no pretenden hundir el libro de Moller ni menoscabar su capacidad ni su estilo; más bien intentan evidenciar algo que presumiblemente sea aplicable a un gran número de datos que se proporcionan a lo largo de The Map of Knowledge: son múltiples los detalles que empujan a creer que, en general, la autora habla de libros capitales de la historia de la ciencia occidental a partir de bibliografía secundaria obviando, por ende, una parte esencial de su alcance y significación. El hablar de algo que se desconoce constituye la frontera entre un pasatiempo, una fabulación de corte histórico en base a disciplinas científicas y un libro académico en base a un estudio más o menos pormenorizado. Casi cada capítulo contiene algún fragmento que carece de rigor o hace alusión a cuestiones que pueden alejarse de la motivación primaria por la que el lector se haya podido acercar al libro de Moller.

El hecho de que la autora dedique los capítulos IV - V del libro a Córdoba y Toledo (Moller, 2019, pp. 99 - 134; 137 - 166) - enclaves cruciales en la transmisión del saber científico en Europa durante la Edad Media - puede ser un acicate para el lector de habla hispana interesado en estos temas. En este sentido, el capítulo más completo (y por mucho) es el que trata sobre la empresa de traducción de textos árabes al latín (como el Almagesto de Ptolomeo) en el Toledo del s. XII del pugno del gran Gerardo de Cremona. La importancia de Toledo como puente cultural entre el mundo árabe y Europa durante la Baja Edad Media queda manifiesta en la descripción del propio itinerario intelectual que el astrónomo Daniel de Morley (s. XII) hizo al obispo de Norwich (Moller, 2019, pp. 163 - 164). En la bibliografía, V. Moller atribuye la noticia a las lecciones que Ch. Burnett impartió en las llamadas The Panizzi Lectures de 1996 (publicadas el año siguiente); pero el caso es que Burnett bien pudo haber extraído los detalles del relato de un ensayo publicado 11 años antes por el gran medievalista Jacques Le Goff (Le Goff, 1986, p. 35). Así, pues, casi mil años después Toledo sigue ejerciendo como canal de transmisión de ideas, aunque esta vez sea entre el viejo continente y el mundo anglosajón.

En un pasaje del libro (Moller, 2019, p. 244), V. Moller hace referencia a The Swerve. How the World Became Modern. Empezaremos la reseña del libro de
S. Greenblatt trayendo a colación uno de los aspectos señalados a propósito del libro de Moller, de nuevo, el de la dificultad que entraña conciliar el rigor informativo con el carácter divulgativo. Al inicio del capítulo IV del libro de Greenblatt leemos:

« Apart from the charred papyrus fragments recovered in Herculaneum and another cache of fragments discovered in rubbish mounds in the ancient Egyptian city of Oxyrhinchus, there are no surviving contemporary manuscripts from the ancient Greek and the Roman world. Everything that has reached us is a copy, most often very far removed in time, place, and culture from the original. And these copies represent only a small portion of the works even of the most celebrated writers of antiquity. » (Greenblatt, 2011, p. 81)

Desde una perspectiva papirológica / filológica tal afirmación necesita ser matizada, pues de lo contrario estaría rozando el disparate. Siendo condescendientes, podríamos pensar que en este pasaje el ganador del premio Pulitzer podría estar refiriéndose o bien a textos del propio Epicuro o bien a eso que técnicamente se conoce como textos 'autógrafos' (Dorandi, 2007, p. 48) ${ }^{7}$; pero no parece que la afirmación de Greenblatt vaya en este segundo sentido, bastante técnico, puesto que ello habría impedido una afirmación tan alejada de la realidad. Ciertamente, casi todo lo que nos queda de los clásicos se ha preservado por medio de copias de sus obras, copias cuyos originales pudieron escribirse poco más de una centuria antes - tal sería el caso de los tratados de Filodemo de Gadara (s. II - I a.C.) encontrados en Herculano - o en ocasiones más de 500 años antes - como sucede con el papiro del s. III d.C. que contiene fragmentos del tratado Sobre la verdad del sofista Antifonte (s.V a.C.) $)^{8}$. El pensamiento de los clásicos nos ha llegado también a través de extractos insertados en obras de autores posteriores que, en un momento determinado, permiten una reconstrucción de los contenidos de lo que pudo ser el texto original; por ejemplo, y por no cambiar de autor, el Protréptico de Aristóteles.

Siendo esto innegable, existen sin embargo miles de restos y fragmentos conservados en las grandes colecciones y archivos papirológicos. Por citar los más representativos desde el punto de vista científico y/o filosófico, de la Antigüedad nos han llegado: el Papiro de Derveni (s. IV a.C.?) (Kouremenos, Parássoglou, Tsantsanoglou, 2006, p. 9); el llamado "Empédocles de Estrasburgo" (s. I a.C.); o el papiro Anónimo de Londres (s. I d.C.) - el papiro (autógrafo) de contenido médico en griego más extenso y completo que se conoce hasta la fecha. La afirmación de Greenblatt no deja de sorprender habida cuenta de que a lo largo de su libro 
da muestras de conocer bien la tradición posterior del epicureísmo a tenor, pongamos, de la exposición de los pormenores relativos al descubrimiento del De rerum natura de Lucrecio en la inmensa biblioteca de la Villa de los Papiros sepultada bajo las cenizas del Vesubio en Herculano (79 d.C.) - con numerosos tratados del epicúreo Filodemo de Gadara (Greenblatt, 2011, pp. 54 - 65); o asimismo, a juzgar por la noticia que Greenblatt da acerca de las monumentales inscripciones epigráficas del s. II d.C. que el epicureo Diógenes de Enoanda (Turquía actual) hiciera esculpir cerca del foro de su ciudad natal; o también, por los detalles codicológicos (Greenblatt, 2011, pp. 155 - 156) que aporta en algunos momentos del relato, especialmente, a la hora de trazar el influjo que el atomismo en general, y el $D e$ rerum natura en particular, ejercieron desde el Renacimiento en adelante en autores como J. Hus, G. Bruno, M. de Montaigne o Th. Jefferson (especialmente en el cap. XI ). Dignas de mención son también las páginas que el autor dedica al paso del rollo de papiro al códice de pergamino, acontecimiento crucial en la historia cultural estrechamente vinculado a la expansión del cristianismo (Greenblatt, 2011, pp. 38 - 40).

Los aspectos que se acaban de mentar conducen a una doble conclusión. Por mor del rigor, Greenblatt se interesa por los primeras etapas de la tradición del epicureísmo pero, por lo general, ese periodo cae fuera de su ámbito de competencia dando lugar a malentendidos, o incluso a errores. Pero por otro lado, al centrar su atención en una época determinada, y por el hecho de circunscribirse a un único texto/autor, el libro de Greenblatt presenta una diferencia sustancial respecto a lo "ambicioso" de la trama de The Map of Knowledge y, por consiguiente, en comparación con el libro de Moller, desde el punto de vista argumental The Swerve se articula y se presenta de una manera mucho más consistente: en este caso, vale eso de "menos es más". Por esta misma razón, no obstante, el lector de espíritu estrictamente positivista encontrará pocos elementos de interés en los capítulos IV - VII del libro de Greenblatt.

The Swerve nace del empeño de mostrar, a partir del hallazgo del De rerum natura, la transición de un mundo a otro, el renacer de una tradición que el teocentrismo medieval imperante y el paradigma creacionista en sinergia con la Iglesia Católica habían relegado al olvido. Pese a esto, y debido a azarsos avatares en la Curia romana, Lucrecio y su libro nunca fueron incluidos en el Index librorum prohibitorium (Greenblatt, 2011, pp. 226 - 227). El epicureísmo no ofrecía ningún viático, no compartía la idea de que la vida era un mar de lágrimas de la que salir era lo mejor que se podía hacer, no constituía una ayuda para la muerte sino una ayuda para la vida.
En este sentido, las doctrinas de Epicuro y de Lucrecio atentaban contra y suponían una grave amenaza para dicho status quo. Apofáticamente, por via negativa, las razones y el alcance de este desafío se plasman magistralmente en el cap. VIII, páginas que a nuestro entender constituyen uno de los puntos fuertes del libro de Greenblatt (Greenblatt, 2011, pp. 185 - 200). Además, las doctrinas contenidas en el De rerum natura parten del supuesto según el cual el fin último es el placer. Dicha premisa iba ya en contra de la mentalidad de muchos de los contemporáneos de Epicuro y de Lucrecio, y como no, horripiló tanto a judíos primero como a cristianos después. Así, cuando Greenblatt (Greenblatt, 2011, p. 223) cita el tratado Sobre el placer (De voluptate) ${ }^{9}$ del humanista L. Valla, defensor a ultranza del epicureísmo y enemigo acérrimo del protagonista del libro, Poggio Bracciolini (s. XV), uno difícilmente puede abstenerse de remitir las palabras del humanista a los famosos "tres golpes" (blows) que S. Freud asestara al geocentrismo, al antropocentrismo y al racionalismo - pilares de la moderna cultura occidental - en su reflexión sobre las dificultades del psicoanálisis:

« 3 blows to narcissism: the cosmological blow when, contrariwise to what he had been credited with for centuries, after the Copernican revolution man must acknowledge that he is no longer the centre of the Universe. The biological blow comes in when man finds out the evidence both in his physical structure and in his mental disposition of his parity with animals. The psychological blow, the third blow, is brought about two major discoveries in psychoanalysis: the life of the sexual instincts cannot be totally restrained, and that mental processes are themselves unconscious, so that 'the ego is not master in its own house ». (Freud, 1953, pp. 351 - 352)

En su cometido por revelar y desvelar los procesos por los que paulatinamente, a partir del Renacimiento, se fueron abandonando los prejuicios de un mundo en declive por otros cada vez más afines a lo que el conocimiento de la época iba poniendo de manifiesto, Greenblatt trae a colación la cuestión de la libertad en oposición a la (pre)determinación, cuestión que por sus ulteriores implicaciones morales se demuestra radical en el esquema de la naturaleza atomista. De hecho, el título mismo del libro apunta directamente a la doctrina del clinamen (declinatio, inclinatio), de la desviación impredecible de la materia del movimiento de los átomos en virtud del cual los epicúreos explicaban la "libertad" en sentido físico, esto es, daban razón de la aparición/creación de nuevas formas en una naturaleza que concebían compuesta de átomos moviéndose en el vacío. Greenblatt hace alusión a este núcleo teórico en la doctrina del Jardín en la página 7 del Prefacio de The 
Swerve, pero no vuelve a remitirse a él hasta el capítulo octavo, usando poco menos de una página para despachar el asunto (Greenblatt, 2011, pp. 188 - 189). En esta ocasión, a nuestro entender, "menos no es más".

En el s. IX, la disputa acerca de la composibilidad de la libertad y de su incompatibilidad con la doctrina de la determinación hizo correr ríos de tinta - y seguramente, para los heterodoxos, también de lágrimas y de sangre - entre las élites de los círculos eclesiásticos encargadas de fijar y hacer prevalecer los dogmas teológicos. Es precisamente en este marco en el que aparece en escena Rabano Mauro (780 - 865), obispo de Maguncia y abad de Fulda. Discípulo de Alcuino de York (el "primer ministro" de Carlomagno) y autor de un libro de carácter enciclopédico titulado De rerum naturis $^{10}$ / Sobre el universo, en su libro Greenblatt nos ofrece el perfil más benévolo y amable de Rabano Mauro (Greenblatt, 2011, pp. 44 - 49), imagen que se sostiene hasta que se cae en la cuenta de que Greenblatt omite el famoso "affaire Godescalco", un importante episodio en el oficio del personaje que transcendiera la historia del monaquismo medieval y omisión que pone en entredicho la inocente actividad erudita de Rabano Mauro.

Godescalco fue un oblatus, su padre lo abandonó en el convento de Fulda a la edad de 6 años. Después de pasar su infancia y adolescencia en la abadía solicitó la exclaustración puesto que la vida monacal no le convencía. Los obispos se la concedieron pero Rabano Mauro, su abad, se la negó y Godescalco fue enviado al convento de Orbais. En la biblioteca, solo, con mucho tiempo, y lejos de Rabano Mauro, Godescalco se enfrascó en las lecturas de los tratados de san Agustín sobre la gracia y la predestinación ${ }^{11}$ : Agustín enseñaba que los hombres estamos predestinados a la salvación o a la perdición eterna, e incluso que la gran mayoría - clérigos y monjes inclusive - íbamos derechos a la condena eterna. No estaba tan claro que Dios fuera bueno ni que quisiera la salvación de todos los hombres. El hombre no sería libre por el mero hecho de serlo sino solo si pertenecía al grupo de los elegidos; sería libre solo aquel hombre a quien la gracia divina había llamado a la libertad. Tal y como algo antes ya había postulado Isidoro de Sevilla ${ }^{12}$ (Mi-

\section{NOTAS AL FINAL}

1 De Euclides no se sabe prácticamente nada, salvo que fundó la escuela de Alejandría y que su actividad tuvo lugar durante el reinado del primero de los Ptolomeos. A Euclides debemos el "principio de identidad de los indiscernibles", el axioma según el cual dos entidades iguales a una tercera son iguales entre ellas $(A=B \wedge B=C \rightarrow A=C)$. gne, 1850, p. 606; Flasch, 2002, p. 40), a quien Godescalco también leyó, la tesis de la doble predestinación (gemina praedestinatio) negaba la libertad. Esta tesis no había sido tomada en consideración por parte de los doctos del círculo de Alcuino, quizás la habían descartado expresamente en tanto que ponía en entredicho la obra entera de Agustín, pues si como Godescalco creía leer en el hiponense estamos, en efecto, predestinados de antemano... ¿qué más daba cómo actuáramos?; ¿Y Jesús, habría sufrido y muerto acaso solo para algunos y no por todos? (Flasch, 1983, p. 189) Incentivo para el libertinaje, revulsivo tanto de los principios del orden social de la sociedad carolingia (la nueva Atenas) como de los postulados de la Iglesia, ante la invectiva de Godescalco los conocedores de Agustín pronto se dividieron en dos bandos. Los sucesores de Alcuino, entre ellos Rabano Mauro, se defendieron dialécticamente y por la fuerza (Flasch, 2002, p. 39) y a resultas de esto Godescalco fue condenado por el sínodo de Maguncia (848). Rabano Mauro, entonces obispo, hizo que lo latigaran delante del resto de prelados y ordenó que lo encerraran en el convento de Orbais, con la expresa prohibición de que no pudiera leer ni escribir. Por esto el retrato de Rabano Mauro en el libro de Greenblatt elude un sesgo del personaje relativamente importante cuando se le vincula a una de las consecuencias fundamentales del epicureísmo.

Finalmente, en cuanto al aparato de la versión de The Swerve que aquí reseñamos, cabe decir que no solo no dispone de notas a pie de página sino que también carece de cualquier tipo de sistema de reenvío intertextual a las numerosas notas y aposiciones listadas en la parte final del libro por capítulo y página (Greenblatt, 2011, pp. 267 - 308). A sabiendas de que se trata de una preferencia absolutamente subjetiva a la hora de disponer la información aneja a un texto principal, el "mutismo" del texto en este sentido no facilita la lectura sino que la hace algo más engorrosa, llegando incluso a confundir al lector, puesto que al acabar el libro este se da de bruces con casi 40 páginas de aclaraciones y explicaciones que le hacen dudar de si la ausencia de llamadas de reenvío a lo largo del texto puede haber mermado su comprensión o, incluso, haberle inducido a llevarse una falsa impresión del libro en su conjunto.

2 [En línea], disponible en: https://webs.ucm.es/BUCM/ blogs//Foliocomplutense/2656.php [consultado el 14 / 2 / 2021] Durante toda la Antigüedad tardía y la Edad Media el libro de los Elementos se conoció de manera indirecta, a través de una versión de Teón de Alejandría (s. IV d.C.). No fue hasta el 1813, con el descubrimiento del Vatica nus graecus 190 (s. X d.C.) por parte de François Peyrard, que se tuvo acceso a una versión anterior a la de Teón. [En línea], disponi- 
ble en: https://digi.vatlib.it/view/MSS_Vat.gr.190.pt.1 y en https://digi.vatlib.it/view/MSS_Vat.gr.190.pt.2 [consultados el 14 / 2 / 2021]

3 El fragmento incluye una breve aposición a pie de página que reza como sigue: «In early 2005 , a French research student discovered a treatise by Galen calle $\mathrm{d}$ On the Avoidance of Grief at a monastery in Thessaloniki. ».

4 Galeno De libris prop. XII 45 [XIX p. 121, 11 K.][en línea], disponible en: http://cmg.bbaw.de/epubl/online/wa galen_scripta_min_2.php?custom $=1 \& p n=185$ [consultado el 14 / 2 / 2021]

5 Galeno De indolentia §16, 1 - 5.

6 Garofalo, Ivan; Lami, Alessandro (2012), Galeno: I'anima e il dolore. De indolentia, De propriis placitis, Milán, BUR, p. VI: " II trattatello de indolentia era, fino a pocchisimi anni fa, noto solo per il titolo e per pochi excerpta in arabo e in ebraico ".

7 En el ámbito de la ciencias filológicas, y también en la papirología, por 'autógrafo' se entiende el fenómeno por el cual una y la misma persona sea el autor y el escriba/escritor de un texto, roles que en la Antigüedad no acostumbraban a ir de la mano. Los papiros literarios de carácter autográfico son más bien raros; en efecto, de los miles de papiros catalogados hasta la fecha solo 20 pueden considerarse autógrafos.

8 P. Oxy. XI 1364 (Cambridge Univ. Libr. inv. add. 6355) + P. Oxy. $52.3647=$ MP3 $92=$ LDAB 230) comprende 13 fragmentos de un tratado de Antifonte titulado De la verdad y constitu-

\section{BIBLIOGRAFÍA:}

Boudon - Millot, Véronique; Jouanna, Jacques; Pietrobelli, Antoine (2010), Galien vol . IV: Ne pas se chagriner, París, Les Belles Lettres.

Dorandi, Tiziano (2007), Nell'officina dei classici. Come lavoravano gli autori antichi, Roma, Carocci

Flasch, Kurt (1983), Agostino d'Ippona, Boloña, II Mulino.

Flasch, Kurt (2002), Introduzione alla filosofia medievale, Turín, Einaudi.

Freud, Sigmund (1953), "One of the Difficulties of Psycho-Analysis". En: Freud, Sigmund Collected Papers IV. Papers on Metapsychology, Londres, The Hogarth Press, pp. 351 - 356, pp. 351 - 352.

Garofalo, Ivan; Lami, Alessandro (2012), Galeno: I'anima e il dolore. De indolentia, De propriis placitis, Milán, BUR.

Garofalo, Maria Luisa (2013), "Galeno. Nuovi scritti autobiografi, Introduzione, traduzione e commento a cura di M. VEGETTI, yen el fragmento filosófico más extenso de un sofista hasta la fecha.

9 « According to my Epicurus... nothing remains after the dissolution of the living being, and in the term "living being" he included man just as much as he did the lion, the wolf, the dog, and all other things that breathe. With all this I agree. They eat, we eat; they drink, we drink; they sleep, and so do we. They engender, conceive, give birth, and nourish their young in no way different from ours. They possess some part of reason and memory, some more than others, and we a little more than they. We are like them in almost everything; finally, they die and we die - both of us completely. »

10 Greenblatt lo cita de esta guisa en su libro, aunque seguramente sea más acertado llamarlo De la diversa naturaleza de las cosas y diversa propiedad de las palabras, y del significado místico de las cosas.

11 Agustín de Hipona De la religión verdadera XII, 23 - 24; La gracia y el libre albedrío II, 3; De la Trinidad XIII, 14 - 16. De dichas lecturas surgió un opúsculo en el que Godescalco resaltaba la importancia que esas doctrinas tomaban en el pensamiento agustiniano. Algunos fragmentos de esas reflexiones se preservaron en obras posteriores de Hincmaro de Reims, de Juan Escoto Erígena, de Ratramno de Corbie y de Lope de Ferrières. El De Praedestinatione de Godescalco fue descubierto mucho más tarde, en 1931, por G. Morin en la biblioteca de Berna.

12 Isidoro de Sevilla, Sententiarum libri tres (Libro de Sentencias) II 6, 198: "Gemina est praedestinatio, sive electorum ad requiem, sive reproborum ad mortem.».

Carocci, Roma 2013, 303 pp", Elenchos. Rivista di Studi del Pensiero Antico 34 (2), pp. 441 - 448.

Greenblatt, Stephen (2011), The Swerve. How the World Became Modern, Nueva York / Londres, W. W. Norton \& Company.

Kouremenos, Theokritos; Parássoglou, George; Tsantsanoglou, Kyriakos (2006), The Derveni Papyrus, Florencia, Leo S. Olschki.

Le Goff, Jacques (1986), Los intelectuales en la Edad Media, Barcelona, Gedisa.

Migne, Jacques Paul (1850), Patrologia Latina vol. LXXXIII, París, $\mathrm{BCU}$.

Moller, Violet (2019), The Map of Knowledge. How Classical Ideas Were Lost and Found: A History in Seven Cities, Londres, Picador

Rashed, Marwan (2011), "Aristote à Rome au lle siècle: Galien, De indolentia §§ 15 - 18", Elenchos. Rivista di Studi del Pensiero Antico 22 (1), pp. 55 - 77. 